\title{
Memorias de Concepción Lombardo de Miramón. Una reflexión sobre el proyecto político fallido de Maximiliano de Habsburgo, Napoleón III y el partido conservador mexicano
}

Ute SEYDEL Universidad Nacional Autónoma de México

\section{Las Memorias en el contexto del discurso histórico construido por mujeres mexicanas nacidas en el siglo XIX}

La participación en el movimiento de Independencia de algunas mujeres mexicanas, como la corregidora Josefa Ortiz de Domínguez, la Güera Rodríguez, María Soto de la Marina, Serrana de Dolores y Leona Vicario, fue de suma importancia para que la sociedad mexicana se concientizara acerca de la capacidad del sector femenino de la población de desempeñar un papel significativo en tanto agente de las transformaciones políticas y sociales del país. La participación femenina en la insurgencia fue asimismo importante para que, décadas más tarde, otras mujeres de la elite se vieran alentadas a dar a conocer por medio de diversos géneros discursivos - los géneros epistolar, biográfico y periodístico, el diario, la poesía patriótica y la narrativa histórica - sus reflexiones acerca de la política e historia mexicanas. Laureana Wright de Kleinhans (1846-1896), Concepción Lombardo de Miramón (1835-1917), Dolores Bolio (1880-1950) y Laura Méndez de Cuenca (1853-1928) figuran entre estas mujeres que, desde su posición privilegiada en tanto hijas o esposas de mineros, diplomáticos, militares, intelectuales y políticos, se ganaron paulatinamente un espacio para divulgar sus interpretaciones y posturas ideológicas acerca de la historia nacional. ${ }^{1}$

Laureana Wright de Kleinhans, autora de numerosos poemas patrióticos, escribió para el periódico Mujeres de Anáhuac, que ella dirigía, biografías sobre mujeres de diversos grupos sociales. Por un lado, recuerda el destino de las que se vieron trágicamente afectadas por los acontecimientos históricos a raíz de la conquista y derrota de los pueblos indígenas y, por el otro, retrata la vida de las que tuvieron un papel destacado en la historia y cultura durante la Colonia y en las primeras décadas del Estado mexicano independiente. ${ }^{2}$ En 1910, el conjunto de estas biografías se publicó de manera

\footnotetext{
${ }^{1}$ Aquí me limito a mencionar a estas cuatro escritoras que se refirieron en textos ficcionales y no ficcionales a acontecimientos y personajes históricos. Un panorama general acerca de la producción literaria de las mexicanas nacidas en el siglo XIX se ofrece en Las voces olvidadas. Antología crítica de narradoras mexicanas nacidas en el siglo XIX (Domenella/Pasternac, 1991).

${ }^{2}$ La revista Violetas de Anáhuac se publicó también bajo la dirección de Wright de Kleinhans y contó con la colaboración de diversas mujeres que escribieron sobre temas como la higiene, la educación doméstica y la instrucción femenina, entre otros temas.
} 
póstuma en el volumen Mujeres notables mexicanas. En la primera de las cuatro secciones se agruparon las biografías sobre la Malinche — considerada como traidora por la biógrafa-, sobre las hijas de Moctezuma y de Xicoténcatl, que pasaron de princesas indígenas a esclavas o concubinas de Hernán Cortés y otros conquistadores, así como sobre las indígenas que se resistieron al bautizo cristiano y trataron de conservar sus costumbres, creencias y prácticas culturales. La segunda sección contiene las biografías sobre diversas mujeres de la época colonial, entre otras, sobre las escritoras y religiosas sor Juana Inés de la Cruz e Isabel de Bonilla, sobre la mística Francisca de San José y sobre doña María Ana Gómez, condesa de la Cortina y fundadora de la orden religiosa de las Hermanas de San Vicente de Paul, así como sobre las filántropas Josefa Vergara y María Josefa Yermo de Yermo, que se hicieron famosas por heredar su fortuna a la ciudad de Querétaro y por liberar a centenares de esclavos, respectivamente. La tercera sección de Mujeres notables mexicanas se centra en las vidas de las mujeres vinculadas con el movimiento de Independencia y la elite política de aquella época: la corregidora Josefa Ortiz de Domínguez, Leona Vicario, la Güera Rodríguez, María Soto de la Marina y Serrana de Dolores. En la cuarta y última sección del volumen se encuentran las biografías acerca de las mujeres coetáneas de Wright de Kleinhans, que como médicas, periodistas, traductoras, profesoras y artistas se abrieron paso en el mundo profesional, hasta entonces un ámbito reservado exclusivamente para los hombres.

Mientras que Wright de Kleinhans destaca en las biografías las aportaciones de las mujeres a la cultura mexicana, así como la participación femenina en sucesos importantes en diversas épocas del pasado nacional y subraya, asimismo, la trascendencia de la actuación femenina, Laura Méndez de Cuenca (1853-1928) se refiere en los cuentos "Un espanto de verdad", "La curva" y "La venta del Chivo Prieto", escritos entre 1890 y 1909 y publicados en 1910 en la colección Simplezas, sólo de modo tangencial a los hechos históricos recientes como la guerra contra Estados Unidos (1846-1847), la pérdida de la mitad del territorio mexicano a esta nación y la Intervención francesa. Como temas típicos de la literatura del romanticismo aparecen en estos cuentos el patriotismo y la preocupación por el destino de la joven nación independiente que se vio amenazada por el imperialismo estadounidense y francés.

Otro acercamiento ficcional a los acontecimientos de la historia mexicana reciente lo ofrece la novela Una hoja del pasado, de Dolores Bolio, concluida en 1918 y publicada en $1920 .^{3}$ Asumiendo el punto de vista de los conservadores, la narradora en pri-

\footnotetext{
${ }^{3}$ Es la primera novela histórica de una narradora mexicana. Siete décadas antes, en 1846, la cubana Gertrudis Gómez de Avellaneda publicó Guatimozín, último emperador de México, la primera novela histórica escrita por una autora en el hemisferio del Caribe y Latinoamérica. Cabe recordar que el género novelístico se empezó a cultivar tardíamente en este hemisferio y apenas en plena lucha por la Independencia se publicó, en 1816, la primera novela: El Periquillo Sarniento de José Joaquín Fernández de Lizardi. Casi veinte años más tarde, en 1839, comenzó a circular la primera novela histórica: Cecilia Valdés, del escritor cubano Cirilo Villaverde. Le siguen numerosas novelas históricas en los diversos países caribeños y latinoamericanos, ciertamente, en su mayoría de la pluma de los hombres.
} 
mera persona, Concha, que es dama de compañía de doña Edelmira Gómez del Valle, recuerda y comenta algunos de los sucesos relacionados con los enfrentamientos bélicos entre los liberales y los conservadores, la Intervención francesa, el Segundo Imperio, el triunfo de los liberales, así como la restauración de la República bajo el gobierno del presidente Benito Juárez y la consecuente reafirmación del laicismo del Estado. Al contrario, doña Edelmira, pese a que pertenece a la aristocracia, fue educada de acuerdo con los valores católicos y del mundo cortesano y se desempeñó incluso como dama de compañía de la emperatriz Carlota, celebra la victoria de Juárez y el sistema republicano, ya que, según ella, la "actitud de conciliación prematura" de Maximiliano "probó su incapacidad militar y política" (Bolio, 1920: 78). Mientras que la novela de Bolio contrasta dos interpretaciones y evaluaciones de los sucesos históricos relacionados con la confrontación entre los liberales y los conservadores, en sus Memorias, que se analizarán en el siguiente inciso, Concepción Lombardo de Miramón los comenta adoptando únicamente la óptica de los conservadores. ${ }^{4}$ Es un texto híbrido en que la autora se propone hacer un recuento de su propia vida desde su niñez hasta los primeros años en el exilio tras la muerte de su esposo, el general Miguel Miramón (1831-1867), así como de la vida de éste en tanto hombre público. Se vincula por ello el discurso autobiográfico con el biográfico, y, para validar sus afirmaciones, ella inserta fragmentos de las cartas de su esposo. Desde una distancia temporal y geográfica, ella evoca, asimismo, con nostalgia una época y forma de vida que llegaron a su fin con la caída del Segundo Imperio.

\section{Memorias de Concepción Lombardo de Miramón: génesis y recepción del texto}

En 1917, a cincuenta años de la muerte de su esposo y tras medio siglo de exilio, Concepción Lombardo de Miramón concluyó en Barcelona sus memorias. No obstante, es muy probable que ella iniciara la redacción de este texto varias décadas antes, puesto que José Manuel Hidalgo y Esnaurrízar menciona que ya en 1891 Eagon Corti consultó un diario escrito por la viuda del general Miramón (Hidalgo y Esnaurrízar, 1978: 172-173).

Pese a que Víctor Durán y José Fuentes Mares consultaran el manuscrito de las memorias para escribir sus respectivas biografías sobre Miguel Miramón, éste quedó inédito hasta 1980, cuando por fin empezó a circular la edición elaborada por la editorial Porrúa. El volumen se compone de dos partes: la primera es conformada por una nota preliminar de Felipe Teixidor, por unos comentarios breves acerca de las ilustraciones

\footnotetext{
${ }^{4}$ En un momento en que el tema de la Revolución mexicana predominaba en la narrativa de México, dos narradoras volvieron a ficcionalizar los acontecimientos relacionados con la guerra contra Estados Unidos y con la Intervención francesa: Patricia Cox en El Batallón de San Patricio (1954) y Sara García Iglesias en El jagüey y las ruinas (1943), respectivamente.
} 
de la edición, así como acerca de la carta en que José Manuel Hidalgo y Esnaurrízar se refirió a la existencia del manuscrito, y por el texto extenso de la viuda; en la segunda parte se encuentran la transcripción de las cartas que Miguel Miramón escribió entre 1858 y 1867 a su esposa; un extracto de la historia militar de Domingo Ibarra, que se refiere a las hazañas militares de Miguel Miramón entre 1838 y $1960 ;{ }^{5}$ el Manifiesto a la Nación que el militar dirigió al pueblo mexicano siendo presidente interino en 1859; la transcripción de las cartas que Miramón envió al general Casanova, y diversos documentos relacionados con la causa instruida a los generales Miramón y Mejía, así como al archiduque austriaco Maximiliano de Habsburgo.

En 1992, la casa editorial Grijalbo lanzó otra edición prologada por Emmanuel Carballo. Para esta edición se cambió el título: en lugar del título escueto Memorias figura Memorias de una primera dama. Además se hicieron modificaciones en cuanto al contenido. Faltan, por ejemplo, todos los documentos que conforman la segunda parte del volumen de Porrúa, de modo que el lector cuenta sólo con las memorias de la viuda y algunos fragmentos de las cartas de Miguel Miramón que ella citó en el cuerpo textual de sus memorias. A diferencia de la edición de Porrúa en que se transcribió el manuscrito sin modificación alguna, en la edición de Grijalbo se corrigió la ortografía y se cambió la sintaxis utilizada en el original, ya que, como señala Emmanuel Carballo en el prólogo, se consideró que el texto de Lombardo de Miramón era difícil de entender (Carballo, 1992: 13). ${ }^{6}$ Por último se eliminaron algunas de las descripciones que la autora hizo de las ciudades europeas que había visitado a lo largo de su vida. Aunque sería digno de evaluar todas estas intervenciones del editor, aquí me interesa comentar sólo el hecho de que falte la segunda parte con los documentos. Al parecer, la intención de Lombardo de Miramón era que éstos se publicaran junto con el texto que ella escribió con base en sus recuerdos y las cartas de su esposo, pues incorporarlos representaba una posibilidad de otorgarle mayor validez a sus propias afirmaciones como testigo de los acontecimientos y a partir de las conversaciones con sus coetáneos, en particular, su esposo. Además, según la historiadora Ramos Escandón, al incluir y citar los textos escritos por hombres, la viuda trató de demostrar la objetividad e imparcialidad de sus juicios con respecto a la gesta militar y las decisiones políticas de Miguel Miramón ( $c f$. Ramos Escandón, 1991: 275). ${ }^{7}$ Obviamente, este propósito no se había logrado tampoco en el volumen puesto en circulación por Porrúa, ya que las cartas y el manifiesto de Miramón, así como los extractos de la historia militar que aparecen ya sea transcritos en la segunda parte del volumen o intercaladas en el cuerpo del texto de las memorias, sólo avalan el punto de vista de los conservadores. El único

\footnotetext{
${ }^{5}$ El periodo cubierto en esta historia militar termina entonces antes de iniciarse, en 1862, la Guerra de Intervención.

${ }^{6}$ Cabe señalar, sin embargo, que no se trata sólo de una corrección de estilo, pues se eliminaron palabras y sintagmas enteros.

${ }^{7}$ Según Ramos Escandón, el positivismo francés formó ya antes de 1867 una actitud intelectual en México que se manifiesta también en el afán de Lombardo de Miramón "por documentar el mayor número de detalles y apoyarse en otros testimonios documentales" (1991: 275, nota 28).
} 
documento que pone en tela de juicio la argumentación de la viuda es la acusación del fiscal que figura entre los documentos de la segunda parte de las Memorias. Pero en el cuerpo del texto, Lombardo de Miramón no entra en diálogo con los documentos escritos desde el punto de vista de los liberales.

\section{Contenido, estructura y perspectiva asumida en las Memorias}

Mientras que en el volumen de Porrúa, las Memorias están divididas en once apartados, en la edición de Grijalbo están organizadas en doce, llevando además títulos que difieren de los utilizados en la edición de Porrúa. Las Memorias comprenden los años 1835 hasta diciembre de 1869, es decir, el periodo de la vida de Concepción Lombardo de Miramón que va desde su nacimiento hasta los primeros dos meses de su tercer año en el exilio. Se caracterizan por un alto grado de linearidad y el respeto a la cronología de los acontecimientos. Sólo existen algunas digresiones en las que la viuda del general Miguel Miramón proporciona informaciones complementarias que considera pertinentes para la mejor comprensión de las decisiones y actuaciones del presidente y militar mexicano.

Concepción Lombardo de Miramón nació el 8 de noviembre de 1835 en el seno de una familia adinerada que comulgaba con la ideología de los conservadores cuyos valores se basaban en la doctrina católica. Su padre, José María Lombardo, un abogado destacado, firmó el acta de Independencia pero, posteriormente, cuando Agustín de Iturbide se proclamó emperador, se distanció de este militar criollo. Fue diputado del Primer Congreso Constituyente y, durante la primera presidencia de Antonio López de Santa Anna, ministro de Hacienda. Siendo apenas una niña de nueve años, Concepción experimentó por primera vez el impacto que la persecución y venganza políticas podían tener en el ámbito de la vida familiar, pues tras la destitución de Santa Anna, los seguidores de este presidente fueron encarcelados, entre ellos, el padre de Concepción, al que ella visitó en prisión.

Aparte de sus reflexiones acerca de la intolerancia e injusticia políticas, en los primeros incisos de sus Memorias, Lombardo de Miramón se refiere a los ritos religiosos y su educación en uno de los centros de instrucción básica para niñas de las familias adineradas, llamados Las Amigas. Sin embargo, la parte medular de sus memorias la constituyen los años como esposa de Miguel Miramón.

Tras haber celebrado su boda, el 24 de octubre de 1858, con este general joven del bando conservador, ella disfrutó durante unos pocos meses de la gloria y posición social que éste alcanzó como militar y presidente interino. Sucediendo a Manuel Robles Pezuela, ocupó este cargo en dos periodos consecutivos: del 2 de febrero de 1859 al 13 de agosto de 1860 y del 16 de agosto al 24 de diciembre de ese mismo año. ${ }^{8}$ Ya los

\footnotetext{
${ }^{8}$ El nombramiento de Miramón como presidente a la edad de veintiocho años se debió a la popularidad de la que gozó, por un lado, porque como cadete del Colegio Militar de Chapultepec había
} 


\section{$100 \square$ MEMORIAS DE CONCEPCIÓN LOMBARDO DE MIRAMÓN}

primeros años de vida conyugal se caracterizaron por frecuentes separaciones, puesto que el joven general participaba en las campañas militares de los conservadores en la Guerra de Reforma (1858-1861). Poco después de la victoria decisiva que los liberales alcanzaron el 22 de diciembre de 1860 en la batalla de San Miguel Calpulalpan, gracias a la ayuda militar de Estados Unidos, la guerra civil terminó, Benito Juárez estableció su gobierno legítimo y Miramón se vio obligado a renunciar a su cargo como presidente y a abandonar México en enero de 1861. Un mes más tarde, tras haberse reunido con su esposa y sus dos hijos en Cuba, el general se exilió con su familia en Francia. En París se encontró con los mexicanos conservadores José María Gutiérrez de Estrada, Juan Nepomuceno Almonte y José Manuel Hidalgo y Esnaurrízar, quienes planeaban con el emperador Napoleón III la creación de una monarquía en México bajo la protección del ejército francés y llevando al trono a un príncipe europeo.

No sólo Lombardo de Miramón y los defensores y amigos de su esposo, sino también la historiadora Lilia Díaz, en el capítulo "El liberalismo militante" de la Historia general de México, reconocen que Miramón se opuso con vehemencia a este plan. Afirman que, según él, no debían de comprometerse ni la independencia ni la soberanía de México sólo para lograr el objetivo de derrocar el gobierno de Juárez. Sin indicar las fuentes en que se basa, Lilia Díaz sostiene, por ejemplo, lo siguiente: "cuando se enteró de los planes monárquicos [Miramón] dijo encolerizado que en México no existía ningún partido monárquico; por el contrario, Santa Anna, en carta dirigida al archiduque, declaró que no un partido sino la inmensa mayoría de la nación anhelaba la restauración del imperio de Moctezuma" (1981: 858).

En lo que se refiere a los planes de establecer una monarquía en México, Lombardo de Miramón relata que el conde Augusto de Morny ofreció incluso a su esposo ingresar a México bajo la protección del ejército francés, pero que en una conversación con ella éste había expresado su indignación:

[...] me han tomado, me dijo, por un miserable, por un vellaco, me han venido a proponer que vaya a México con las tropas francesas, me han ofrecido, si acepto, una fuerte suma de dinero, asegurándome que si las cosas van mal, podía vivir tranquilamente con mi familia en Europa [...], que al oir aquella propuesta di un puño sobre la mesa y dije al Conde que prefería morir de hambre en el extranjero, quedándome de emigrado, que hacer ese odioso papel (Lombardo de Miramón, 1980: 406). ${ }^{9}$

Empero no existe documento alguno que compruebe que Miramón haya enunciado estas palabras, y el lector no sabe qué tan fiable es la memoria de la viuda cuyo propósito no es sólo hacer en sus Memorias un recuento de los sucesos importantes, sino

luchado, el 13 de septiembre de 1847, contra el ejército invasor de Estados Unidos y, por el otro, porque en la guerra civil contra los liberales había triunfado en varias ocasiones.

${ }^{9}$ En todas las citas tomadas de la edición de Porrúa, la ortografía, puntuación y sintaxis corresponden al original. 
también proporcionar información que favorezca la creación de una imagen positiva acerca de su esposo. ${ }^{10}$ Pese a la imposibilidad de comprobar que el general se expresara con estas palabras, lo que es de conocimiento general, no obstante, es que Miramón no apoyó al ejército francés durante la Guerra de intervención. Se sabe además que tanto los monarquistas mexicanos como el conde Morny y el emperador Napoleón III se disgustaron a causa del desaire y ya no volvieron a invitar al matrimonio Miramón. La situación en París se tornó incluso tan intolerable para los dos que decidieron trasladarse a España en julio de 1861.

Es pertinente subrayar, sin embargo, que a pesar de su rechazo verbal en 1861 al ofrecimiento de internarse en México bajo la protección de las tropas extranjeras, en enero de 1862, cuando las tropas de Inglaterra, España y Francia desembarcaron en Veracruz, Miramón intentó internarse en México junto con ellas. ${ }^{11}$ Sólo porque los ingleses lo reconocieron y recordaron que como presidente interino se había apoderado de los fondos de sus bonos para pagar el sueldo de los soldados mexicanos, el plan de Miramón fracasó, pues lo embarcaron inmediatamente en un buque de guerra inglés para que se regresara a Cuba y se trasladara posteriormente a Europa. En cuanto a los motivos que impulsaron a Miramón a tratar de ingresar a México junto con las tropas de la alianza tripartita, su viuda comenta que "la vida sedentaria que hacía, la inacción en que estaba y la preocupación que tenía por los asuntos de México, lo tenían triste y descontento" (Lombardo de Miramón, 1980: 414). ${ }^{12}$ Ella no parece haberse percatado, no obstante, que a raíz de las cartas que había recibido de sus amigos conservadores exiliados en Cuba, su esposo cambió de opinión y ya no quiso mantenerse al margen de la Guerra de Intervención, hecho que el fiscal Manuel Azpíroz utilizaría más tarde para fundamentar su acusación en contra de Miramón. ${ }^{13}$

\footnotetext{
${ }^{10}$ Ya que Lombardo de Miramón alcanzó a su esposo en París, se interrumpió la correspondencia entre ellos, de modo que no existen cartas en que el general fijara su postura acerca de este ofrecimiento del conde Morny. Hay una carta del 10 de enero de 1861 escrita en su trayecto hacia el exilio y la siguiente carta, incorporada en el cuerpo del texto de las Memorias, es fechada el 16 de junio de 1862, cuando, tras haber recorrido diversos países europeos con su familia, Miramón se encontraba en Berlín.

${ }^{11}$ La viuda recuerda estos hechos del siguiente modo: "Mi esposo llegando a La Habana, se unió con el P. Miranda, con Don Antonio Haro, el Coronel Rodríguez y otros conservadores desterrados que se encontraban en Cuba, junto con ellos se embarcó con dirección a Veracruz; al llegar a ese puerto, se encontraron con los Gefes que iban mandando la intervención, los cuales no se opusieron al desembarque de los conservadores mejicanos; pero el inglés, Sir Charles Wyke, se opuso al desembarque de mi esposo, pretendiendo que era el responsable del atentado de su Gobierno de haberse apoderado de los fondos de los bonos Jecker que estaban depositados en la Legación inglesa" (Lombardo de Miramón, 1980: 415).

${ }^{12}$ Hay una errata en la edición Memorias (1980: 414), ya que se indica diciembre de 1862 en lugar de 1861 como fecha en que Miramón abandonó a su esposa en España para ir a Cuba y tomar una resolución con respecto a su regreso a México, que emprendería a principios de 1862 tras el arribo, en Veracruz, de los buques de guerra de la alianza tripartita.

${ }^{13}$ En los autos se consigna el interrogatorio a Miguel Miramón de la siguiente forma: "preguntando: para que conteste el cargo que tiene de haber tratado de desembarcar a principios de 62 en el puerto de Veracruz, cuando lo ocupaban las fuerzas de la triple alianza en virtud de la Convención de Londres, para ofrecer sus servicios a la intervención extranjera, o a lo menos para volver bajo el
} 


\section{$102 \square$ MEMORIAS DE CONCEPCIÓN LOMBARDO DE MIRAMÓN}

Nuevamente exiliado en Europa, durante los diecisiete meses en que en México se libró la Guerra de Intervención, Miramón tuvo que resignarse a la inactividad, pasando el tiempo con viajes a diversas ciudades europeas y rusas y acudiendo a los eventos culturales en las metrópolis del viejo continente. Sin poder cambiar el curso de los acontecimientos se enteró por medio de cartas y relatos de sus amigos, así como por medio de los periódicos, que los mexicanos monarquistas seguían impulsando la idea de crear una monarquía en México bajo la protección del Imperio francés y que, además, habían resuelto ofrecer el trono al archiduque Maximiliano de Habsburgo, plan que llevó al rompimiento de la alianza entre los gobiernos de Francia, Inglaterra y España. Mientras que las tropas inglesas y españolas abandonaron México, las francesas avanzaron hacia la ciudad de México. Pese a su victoria sobre los franceses en la batalla del 5 de mayo de 1862, el ejército del Gobierno constitucional mexicano no logró la victoria decisiva y el 31 de mayo de 1863 se vio obligado a retirarse de la capital mexicana. Una vez consumado el triunfo de la intervención bajo el general Achilles Bazaine el 7 de junio de 1863 y tras la instalación de la Regencia en la ciudad de México por el general Forey el 25 de junio de 1863, las tropas francesas cometieron muchos abusos contra la población mexicana, establecieron las cortes marciales e introdujeron la pena de muerte, por lo que se volvieron impopulares, no sólo entre los partidarios de los liberales, sino también entre los conservadores.

El 8 de julio de 1863, la asamblea de los 215 notables decidió que el futuro gobierno de México debía ser una monarquía (Lombardo de Miramón, 1980: 460). ${ }^{14}$ Como relata Concepción en sus memorias, ya que la Regencia no logró controlar los abusos contra los mexicanos, "la gente honrada, entre ella muchos liberales moderados [optaron] por

amparo de ella al país de donde había salido a causa de su responsabilidad política anterior; pues que si bien se vio estrechado a alejarse de nuevo del territorio mexicano, porque el representante del Gobierno de Inglaterra lo reclamaba para que fuese juzgado, o pedía su castigo por la violación de los sellos y apoderamiento de los fondos; la misma protección que los agentes franceses le otorgaron, y también tal vez los españoles, para que se salvase del peligro que le amenazaba, es cuando menos un vehemente indicio de su complicidad en los planes del Gobierno francés y tal vez el español, que se venían a desarrollar en México, y cuya iniquidad él mismo ha conocido, según su propia confesión al mismo tiempo que el referido amparo de los extranjeros que de hecho estaban en guerra con el Gobierno constitucional, es una prueba completa de que se valía de la intervención extranjera para eludir la responsabilidad en que había incurrido por su conducta política en la guerra civil [la ortografía en esta y las demás citas de los autos corresponde al texto reproducido en las Memorias]" (Ejército de Operaciones, 1980: 898-899).

No convencen del todo las palabras que Miramón pronuncia en su defensa negando el cargo: "porque su intento de volver al país a principios de 62, sólo tenía por objeto el poder ver de cerca la conducta de los interventores extranjeros, con cuyos proyectos no estaba de acuerdo desde entonces, y los que más bien trataba de contrariar, aunque no le era posible, porque el Gobierno de México lo había escluido nominalmente de la amnistía que concedió a todos los demás que le habían hecho la guerra; y que la protección que le concedió el general Prim, y por su influencia el representante de Francia, fue un servicio amistoso al mismo tiempo que el deber que tenía dicho general de oponerse al abuso que pretendían cometer los ingleses" (Ejército de Operaciones, 1980: 899).

14 Por error, en la edición de Grijalbo, Memorias de una primera dama, se menciona la cifra de 150 notables ( $c f .1992: 151)$. 
la monarquía a fin de que se establesiese un gobierno nacional, que diera la paz al país y lo librase de la dominación francesa" (1980: 462).

Ante estas circunstancias, fue difícil para Miramón determinar el futuro papel que podía desempeñar en México. Por lo pronto ni conservadores ni liberales deseaban su presencia en el país, los primeros porque se había negado a apoyar el plan de traer al archiduque Maximiliano como emperador a México, los segundos porque había desconocido la Constitución promulgada en 1857 por este partido, había combatido a los liberales en la Guerra de Reforma de 1858 a 1861 y seguía defendiendo el principio católico. ${ }^{15}$ Además, se había enemistado con los franceses al rechazar el ofrecimiento del conde Morny de internarse bajo la protección gala a México. ${ }^{16}$ A finales del mismo mes y correspondiendo a la petición del arzobispo de Puebla, don Pelagio de Labastida, Miramón decidió llegar de incógnito a México y se sorprendió de que el general Forey, el vizconde Saligny y varios oficiales del estado mayor le comunicaran unos días más tarde que la Regencia requería de sus servicios; según Lombardo de Miramón, mientras ella hubiera preferido que su esposo adoptara una postura neutral, a él le atrajo la idea de poder formar una división militar que constituiría la base de un ejército nacional que reprimiría los abusos de la fuerza de ocupación francesa (1980: 462).

Pero cuando en octubre de 1863 el general Forey encargó formalmente a Miramón crear una división, los fines que perseguía se distinguían de los que el general mexicano tenía, pues el propósito de la división debía ser la defensa del gobierno de la Regencia contra los liberales, en lugar de permitir que esa fuera el primer paso en la creación de un ejército autónomo mexicano. Por ello, refiriéndose a la primera reunión entre el general mexicano y el francés y el posterior encargo oficial hecho por Forey en una carta, Lilia Díaz sostiene que Miramón "llegó a México a fines de julio y a los pocos días se adhirió a la intervención francesa y a la monarquía proclamada en México" (Díaz, 1981: 870).

\footnotetext{
${ }^{15}$ Por sus méritos en la defensa de los intereses de la Iglesia católica en México, Miramón recibió incluso de manos del papa Pío IX la Gran Cruz.

${ }^{16}$ En varias cartas dirigidas a su esposa, que ya había salido de Francia en agosto de 1862 para regresar a México vía Nueva York y Cuba, Miramón expresó que no sabía qué partido tomar. El 3 de junio de 1863, estando ya en Brownsville y averiguando la mejor forma para internarse en México, envió las siguientes líneas: "Entre tanto he escrito a Mejía, al joven Larrumbide y sus fuerzas, espero que muy pronto las del primero y las de Larrumbide vendrán a mi encuentro. Después de lo acontecido en Puebla, créete que he quedado un momento suspenso sobre lo que convendría mejor al país. ¡Qué desgracia que Juárez y sus compañeros sean tan bandidos!; es imposible ponerse uno al lado de Carvajal, Cuéllar, Aureliano, etc., por otra parte, los franceses son intolerables y mucho me temo que México se convierta en ruinas y cadáveres" (Miramón, 1980: 768). Véase también la carta del 15 de julio de 1863 en que Miramón se refiere de nuevo a su dilema: "aún no he resuelto nada sobre el partido que adoptaré, por un lado la Nación y por otra [sic] los bandidos que ecsisten en el poder me mantienen irresoluto: quiera el Espíritu Santo darme luces para dar los primeros pasos" (1980: 770). Haciéndose eco de estas cartas, Lombardo de Miramón describe la situación de su cónyuge del siguiente modo "sin saber dónde dirijiría sus pasos, sin saber qué partido tendría que tomar; abandonado de sus amigos los concervadores, odiado de Juárez, que le había serrado las puertas de su patria, y malvisto de los franceses a quienes había negado su apoyo... ¡Sólo Dios lo podía sacar de tan peligrosa y difícil situación!” (1980: 455).
} 


\section{MEMORIAS DE CONCEPCIÓN LOMBARDO DE MIRAMÓN}

De acuerdo con sus cartas, Miramón no logró cumplir con las órdenes recibidas por Forey, ya que Napoleón III destituyó a este último de su cargo como mariscal de Francia y nombró a Bazaine como sucesor. Tras varios meses de ociosidad y falta de armamento y coordinación, así como dada la orden del nuevo mariscal que, en caso de ataque, Miramón tendría que ponerse bajo las órdenes del jefe de la Brigada francesa sin saber, no obstante, qué lugar ocuparía, el general mexicano solicitó el 16 de enero ser relevado de su cargo. ${ }^{17}$

Así pareciera que, en un primer momento, Miramón estuvo dispuesto a luchar del lado del ejército francés contra los liberales y que este plan sólo se frustró dado el cambio en el mando del ejército invasor y a causa de las intrigas que tramaron Almonte y Bazaine en contra del general mexicano. Éstos, enterados de la oposición de Miramón al establecimiento de una monarquía bajo la protección del ejército francés, desconfiaban de su lealtad y temían que con una división bajo sus órdenes iba a combatir al ejército francés. Por ello, Bazaine incluso ordenó vigilar la casa de Miramón ( $c f$. Lombardo de Miramón, 1980: 467-468).

Mientras que el establecimiento de la Regencia en la capital mexicana había obligado a los liberales a replegarse, a dejar las ciudades importantes del interior en manos del ejército franco-mexicano casi sin ofrecer resistencia y a establecer su gobierno sucesivamente en diversas ciudades - San Luis Potosí, Monterrey, Saltillo y El Paso del Norte-, la comisión de los monárquicos había entablado negociaciones con Maximiliano en su castillo de Miramar. Cuando la delegación mexicana presidida por Gutiérrez Estrada ofreció en octubre de 1863 la corona al archiduque austriaco, éste la aceptó bajo la condición de que se realizara un plebiscito en México para ratificar así el voto de la Asamblea de Notables en favor de la creación de una monarquía y asegurarse de un amplio respaldo por parte de la población mexicana. Ya que era imposible realizar el plebiscito en México que se encontraba dividido en estados gobernados por la Regencia, por un lado, y por los liberales, por otro, los monarquistas trataron de conseguir la mayor cantidad de firmas posibles. A pesar de las firmas recabadas, el emperador austriaco Francisco José se negó a dar su consentimiento para la coronación de su hermano en tanto emperador de México. Una vez presentadas las actas con las firmas, ni las objeciones de su hermano ni las advertencias de los diplomáticos y políticos austriacos — entre ellos del conde Rechberg — acerca de los riesgos de aceptar la corona de México hicieron desistir a Maximiliano. ${ }^{18}$ A propósito de estos hechos, Concepción Lombardo de Miramón reconoce la prudencia inicial de Maximiliano de

\footnotetext{
${ }^{17}$ Véase las cartas del 7 y 16 de enero de 1864 (Miramón, 1980: 789-790).

${ }^{18}$ Cabe señalar que el conde Rechberg había sido embajador austriaco en Francia en 1856 y había transmitido en 1863, en calidad de ministro de relaciones exteriores del emperador austriaco, el ofrecimiento de la corona mexicana a Maximiliano; sin embargo, a partir de sus experiencias como diplomático y ministro, advirtió también al joven archiduque de los riesgos de aceptarla dada la inexistencia de un partido monárquico en México. Del mismo modo, los embajadores austriacos en Madrid y Roma así como el arzobispo de Puebla, don Pelagio de Labastida, comunicaron a Maximiliano su escepticismo con respecto a la posibilidad de establecer una monarquía duradera en México.
} 
exigir la realización de un plebiscito en México y considera, por un lado, que fue engañado por la delegación mexicana y, por otro, convencido por Carlota a embarcarse en la funesta empresa de aceptar la corona mexicana e incluso a renunciar a los derechos de sucesión a la corona de Austria: "Desgraciadamente, el Archiduque Maximiliano tenía por esposa una Princesa ambiciosa que soñaba con un trono, y así fue que a instancias de la Archiduquesa Carlota, y a los ruegos del Presidente de la comición mejicana, el Señor Gutiérrez Estrada, el Archiduque desidió a renunciar a sus derechos al betusto trono de los Habsburgo para señir la corona del infortunado Emperador Moctezuma" (Lombardo de Miramón, 1980: 469).

La coronación se verificó el 10 de abril de 1864 en el castillo de Miramar, el 28 de mayo los recién coronados llegaron a Veracruz y el 12 de junio del mismo año hicieron su entrada a la ciudad de México, donde fueron recibidos como los virreyes en tiempos de la Colonia. Ya que Maximiliano había prometido el restablecimiento de la Orden de Guadalupe, reinaba el entusiasmo y frenesí entre los conservadores ricos.

Sin embargo, el entusiasmo duró poco tiempo, ya que en su intento de conciliar los bandos mexicanos en conflicto para asegurarse del mayor apoyo posible, Maximiliano empezó a rodearse de algunos liberales moderados e incluso nombró a uno de ellos, Fernando Ramírez, como ministro de Estado, pese a que, meses antes, éste se había rehusado a participar en la Asamblea de Notables que se había creado con la finalidad de votar en favor de una monarquía. Además, influenciado por Bazaine, quien lo informó sobre la oposición de Miramón a los planes de los monarquistas y de su negativa de ponerse bajo las órdenes del ejército francés, Maximiliano decidió enviar al general mexicano a Prusia supuestamente para que aprendiera estrategia militar y conociera la organización del ejército prusiano para luego imitarla al reformar las fuerzas armadas de México.

Para cumplir con esta misión militar, Miramón abandonó México el 8 de noviembre de 1864. Sin embargo, era un secreto a voces que se trataba de un destierro velado. Las cartas a su esposa muestran que en el fondo no tuvo una tarea bien definida y que pasó muchas horas de ocio y se dedicó a disfrutar la vida cultural de Berlín y a atender las invitaciones del rey de Prusia.

Estando en Roma, en carta fechada el 23 de abril de 1865, Miramón expresó su dilema moral y de principios porque, por un lado, sentía su deber vencer a Juárez por sus leyes anticlericales, pero, por otro, tampoco quería luchar en favor de Maximiliano, al que consideraba también como enemigo de la causa del clero mexicano y además como violador de la soberanía e independencia de México:

Proclamadas vijentes las leyes de Juárez contra las cuales luché por algún tiempo, y por las cuales ha sido toda la cuestión, no me parece honroso (aunque sea político) que obedesca a Maximiliano sólo porque es estranjero y más fuerte que Juárez; creo que si presto obediencia seré confundido con todos los hombres sin fe y sin conciencia que cambian de política y partido como de ropa limpia; muy bien sé 
que si a alguien aprovecha esto, no sería a mí, es decir, materialmente, pero con ello cumplo con mi conciencia y con mi voluntad (Miramón, 1980: 839). ${ }^{19}$

En el fondo, Miramón había defendido siempre el principio católico, la soberanía mexicana y un sistema político republicano, pero de orientación conservadora y no liberal. Queriendo ser fiel a sus principios no consideró tampoco como una alternativa viable aceptar la oferta de Manuel Doblado, un liberal enemistado con Benito Juárez, de crear una tercera fuerza política entre liberales y conservadores en favor del restablecimiento de la República. Pese a la negativa de Miramón de unirse a las filas de los liberales, los liberales moderados que habían aceptado cargos en el gobierno imperial temían al igual que los franceses que Miramón pudiese aliarse con sus antiguos correligionarios y favorecían por ello que el destierro del general se prolongara.

Por fin, fastidiado por la reducción de su sueldo por parte de Maximiliano, la inactividad y la vaga promesa del emperador de ofrecerle el lugar que merecía una vez que los franceses hubiesen abandonado México, Miramón renunció a su cargo y se fue en verano de 1866 como observador a la guerra entre Prusia y Austria. Pese a su oposición al imperio del archiduque austriaco en México y a pesar de haber gozado durante meses de la hospitalidad del rey de Prusia, Miramón simpatizó con la causa de los austriacos. Lo que aparentemente determinó su simpatía con la casa de Austria es el hecho de que fuera una monarquía católica.

Sin embargo, parece ser una ironía del destino que meses antes, con el reconocimiento de las Leyes de Reforma, que previeron la desamortización, confiscación y nacionalización de los bienes de la Iglesia en México, así como el principio de laicidad del Estado, el monarca católico, Maximiliano, hubiese ocasionado el rompimiento de las relaciones con la Santa Sede y la partida del nuncio y diversos obispos de México. Es pertinente recordar que el manejo poco cauteloso de las relaciones diplomáticas con el Vaticano provocó un mayor aislamiento de Maximiliano y sus seguidores en el ámbito nacional. Ni siquiera las negociaciones del padre de origen alemán, Agustín Fischer, llevaron ni al restablecimiento de las relaciones diplomáticas ni a la celebración de un concordato entre el emperador mexicano y el papa Pío IX ${ }^{20}$ El papa no aceptó intervenir como intermediario para convencer a los monarcas católicos europeos, el austriaco Francisco José y el francés Napoleón III, de ofrecer apoyo y protección a Maximiliano.

Cuando las tropas francesas se retiraron, Miramón accedió a hacer un intento para organizar un ejército autónomo mexicano y salvar el imperio y la vida de Maximiliano, pues el imperio peligraba tras el retiro de las tropas francesas. El general mexicano desembarcó en México y trató de defender Querétaro contra el ejército de los liberales, que contaba con un renovado apoyo por parte de Estados Unidos, gracias a que en esa

\footnotetext{
${ }^{19}$ En la cita no se corrigieron los errores de ortografía, sino que la carta se reproduce tal como se encuentra transcrita en la segunda parte de las Memorias de Lombardo de Miramón.

${ }^{20}$ El padre Agustín Fischer, en tanto consejero de Maximiliano, estuvo de 1865 hasta principios de 1867 en el Vaticano para llegar a un concordato con respecto a la situación de la Iglesia en México, pero no logró acuerdo alguno con el papa.
} 
nación se había terminado la guerra de secesión, lo que le permitió volver a implementar su política exterior de acuerdo con los principios delineados en la doctrina Monroe en contra de intervenciones europeas en el continente americano. ${ }^{21}$

Tras su derrota y captura en el sitio de Querétaro, posibles luego de la traición del coronel Miguel López en la madrugada del 15 de mayo, el 14 de junio de 1867 los generales mexicanos Tomás Mejía y Miguel Miramón, así como Maximiliano, fueron enjuiciados por delitos en contra de la independencia y seguridad de la nación y en contra del orden y la paz pública, con base en las leyes que Juárez había promulgado el 25 de enero de 1862, es decir, a los pocos días de haberse iniciado la Guerra de Intervención. Pese a la indignación de los soberanos europeos y a la petición de aplazar el fusilamiento, que fue girada al presidente Benito Juárez por parte del embajador de Prusia, así como a pesar de la petición de indulto por parte de la princesa prusa Agnés de Salm Salm y Concepción Lombardo de Miramón, Juárez no otorgó el indulto a ninguno de los tres prisioneros, y el 19 de junio de 1867 fueron ejecutados. ${ }^{22}$

Luego de haber delineado los hechos políticos y militares considero pertinente comentar varios de los juicios que la viuda del general conservador emitió en sus $M e-$ morias sobre los diferentes actores políticos de su tiempo y los acontecimientos que desembocaron en la captura, el juicio y el fusilamiento de su esposo. Acerca de los juaristas afirmó que actuaban sin moral, y los tachó de anticristianos y antipatrióticos. Reiteró que Juárez comprometió la soberanía nacional al firmar el tratado McLaneOcampo con Estados Unidos. Sostuvo además que éste sólo pudo financiar su campaña contra los conservadores y el imperio de Maximiliano gracias a las fuertes sumas que el gobierno de aquella nación envío a los liberales. Según Lombardo de Miramón, los republicanos obtuvieron también sus recursos por medio del botín entregado por bandoleros y asaltantes, que se apostaban en los caminos del territorio nacional para asaltar a los viajeros.

A su vez, la descripción que realiza Lombardo de Miramón de Benito Juárez refleja su actitud racista y su prejuicio social que emite desde su posición en tanto hija de criollos ricos:

Juárez era hijo del pueblo, nacido en el Estado de Oaxaca, y de pura raza indiana. [...] Como todos los de su raza era lampiño y en su cara brillaba la completa

${ }^{21}$ Basándose en esta doctrina, vigente desde el 2 de diciembre de 1823, Estados Unidos se propuso impedir cualquier intromisión de las antiguas potencias imperiales europeas en las Américas.

${ }^{22}$ Cabe señalar que, en diciembre de 1873, el famoso cuadro La denegación del perdón a Maximiliano, del pintor Manuel Ocaranza, fue exhibido en la XVII Exposición de la Escuela Nacional de Bellas Artes. Existe una reproducción del cuadro en el Catálogo de las exposiciones de la Antigua Academia de San Carlos de México, 1850-1898. México: UNAM, Instituto de Investigaciones Estéticas, compilado por Manuel Romero de Terreros (1963: 458); pero el cuadro se encuentra extraviado. Ya que el presidente Juárez aparece impasible e indolente a pesar de que la princesa Salm Salm se encuentre de rodillas frente a él y la esposa de Miramón con sus dos hijos en el segundo plano detrás del presidente, este cuadro posiblemente no convino a la imagen que la historia oficial quiso crear acerca de Juárez y por eso no se volvió a exhibir ni se conoce, en la actualidad, su paradero. 


\section{$108 \square$ MEMORIAS DE CONCEPCIÓN LOMBARDO DE MIRAMÓN}

ausencia de la barba y del bigote; esto hacía más notable su espaciosa boca, que parecía dilatarse bajo su pequeña y ancha nariz. [...], pero lo que más llamaba la atención en aquel hombre, era la perfecta impasibilidad de su frío semblante, que al verlo se hacía uno la ilución de estar delante de un ídolo axteca (1980: 588).

Contrasta la caracterización que ella ofrece del presidente de origen indígena con la que efectúa de Maximiliano. Subraya que era de "elevada estatura, de formas regulares y cabeza herguida, demostraba en su porte la nobleza de su raza"; afirma que "su tez blanca como el marfil, su cabellera rubia y sus expresibos ojos azules daban a su fisonomía un simpático y agradable aspecto" (Lombardo de Miramón, 1980: 485).

Por otra parte, acerca de Estados Unidos y su responsabilidad en la caída del imperio afirma:

El mayor y más poderoso enemigo de ese naciente Imperio, eran los E. Unidos, y se puede decir con certeza, que ese poderoso enemigo fue el único, secundado por Napoleón III, que destronó al Emperador Maximiliano.

La República Norte Americana no podía ver con buenos ojos el engrandecimiento y el progreso en nuestra amada patria, ni que hubiese un gobierno de orden y estable, que fuese respetado por las grandes potencias de Europa, y que garantizase a éstas, la vida y los intereses de sus conacionales. [...] Sin el apoyo de los E. Unidos, Juárez y todos sus secuaces, hubieran sido impotentes para derrocar el Imperio; pero ya eso era cuestión vieja, y el método adoptado por la ladrona República desde muchos años atrás, fue siempre, el fomentar en México la guerra cibil, para sacar luego la castaña con la mano del gato (Lombardo de Miramón, 1980: 515).

En esta severa crítica a la política de Estados Unidos, Lombardo de Miramón hace caso omiso del hecho de que la estrategia del país vecino de aprovechar la división existente entre diversos grupos sociales y políticos mexicanos sólo funcionó porque los partidos y diversos grupos de interés en México favorecían la búsqueda de alianzas con otras naciones para así hacer prosperar sus intereses partidistas y poder triunfar sobre sus adversarios internos. Así, mientras que los conservadores buscaron el apoyo europeo, los liberales consiguieron la ayuda financiera y militar de Estados Unidos.

Dado el odio que Lombardo de Miramón siente hacia Juárez y sus partidarios, tilda al partido liberal como partido demagógico y establece un paralelismo entre la ejecución de Iturbide, por un lado, y la de Maximiliano, por otro: "Otro emperador hubo en México, el inmortal Yturbide, mandado fusilar el año 1825 por el partido demagogo mexicano, a quien había dado independencia y patria" (Lombardo de Miramón, 1980: 645). ${ }^{23}$

Por otro lado, mientras que otros textos de la época, así como diversos historiadores, defendieron a Maximiliano, ${ }^{24}$ ya que al igual que los liberales abogó por la laicidad del

\footnotetext{
${ }^{23}$ Hay una errata en las Memorias, pues Iturbide fue fusilado en 1824 y no en 1825.

${ }^{24}$ Lilia Díaz hace incluso hincapié en la magnanimidad de Maximiliano al pedir a Juárez el indulto para Miramón y Mejía y al expresar su deseo de ser la única víctima (1981: 895). Por su parte, corres-
} 
Estado, rompió las relaciones con el nuncio y el clero más influyente y rico mexicano en vez de derogar las Leyes de Reforma promulgadas por Juárez en lo que atañe a la desamortización y nacionalización de los bienes de la Iglesia y devolvió, al contrario, a algunas comunidades indígenas las tierras que éstas habían perdido a raíz de las Leyes de Reforma, Lombardo de Miramón destacó las torpezas y la falta de sentido de realidad del emperador, así como su desconocimiento de las políticas internacional y mexicana.

Como uno de los errores del emperador que la autora de las Memorias consigna, figura el hecho de que haya enviado a Miramón a Berlín para que aprendiera estrategia militar. Esta medida de Maximiliano no sólo alejó del territorio nacional a uno de los generales conservadores de mayor mérito, sino que también despertó las suspicacias de los gobiernos de Francia y Estados Unidos, porque ambas potencias querían impedir la creación de un ejército autónomo imperial en México y ninguna de las dos potencias hubiera permitido la intromisión de Prusia en México. ${ }^{25}$ Poco después, Napoleón III decidió privar a Maximiliano de su protección y apoyo militares, mientras que la ayuda financiera de Estados Unidos a los liberales contribuyó a la superioridad de su ejército por sobre el de los conservadores. Además, en el sitio de Querétaro, militares estadounidenses luchaban bajo el mando del general Mariano Escobedo en las filas de los liberales.

Lombardo de Miramón señala dos errores más de Maximiliano que, según ella, ocasionaron el trágico desenlace del proyecto de fundar en México una monarquía llevando a un soberano europeo al trono. En primer lugar menciona la negativa de derogar las Leyes de Reforma, lo que provocó que el emperador se enemistara con los conservadores y el clero mexicano, grupos que inicialmente lo habían apoyado y, en segundo lugar, la viuda hace hincapié en que Maximiliano otorgó al general Leonardo Márquez poderes omnipotenciarios durante el sitio de Querétaro, desconociendo el hecho de que este general aún sintiera rencor hacia él, pues al enviarlo a Jerusalén para que fundara un convento, lo había humillado en su honor militar. Para cobrar venganza, este general no entró en combate cuando los liberales atacaron Querétaro. Esto hace evidente que Maximiliano no sólo cometió errores políticos y estratégicos, sino que también careció de conocimientos acerca de la psique humana.

pondiendo a sus respectivos intereses nacionales, la princesa Agnés de Salm Salm (1869) y la condesa Reinach Foussemagne (1925) defendieron la imagen de Maximiliano.

${ }^{25}$ El secretario de Estado, Seward, había rechazado reconocer al imperio y establecer relaciones diplomáticas con él, puesto que éste tenía una actitud de revolución contra la autoridad soberana de México y se basaba en un ejército extranjero y no en la voluntad libre del pueblo mexicano. Tampoco accedió a reconocer al imperio cuando el gobierno francés ofreció retirar sus tropas. Según Seward, Estados Unidos mantenía relaciones amistosas con el gobierno republicano, por lo que no podía reconocer un gobierno que se había impuesto a la fuerza (Díaz, 1981: 889-890). Por otro lado, la decisión de enviar a Miguel Miramón a Prusia es también difícil de entender si se toma en cuenta que, en el contexto de la fundación de los Estados nacionales europeos, Prusia y Austria rivalizaban por la hegemonía en Europa, lo que desencadenó la guerra entre ambas monarquías en 1866. 
A propósito de los juicios que plasma Lombardo de Miramón en sus Memorias, cabe destacar por último que ella se hace eco de los discursos misóginos de su época en contra de las mujeres de una amplia formación intelectual. Por ejemplo, afirma acerca de los motivos para la locura de Carlota:

Las graves preocupaciones que había tenido la soberana en aquellos últimos meses, su orgullo altamente ofendido, y la idea del triste porvenir que a ella y a su esposo les esperaba en Europa después de la audiencia con Pío IX en la que había recibido una completa negativa del Pontífice, a su pedido, determinaron en la Emperatriz Carlota, la pérdida completa de la razón y se declaró su locura.

Otra cosa pudo tener parte en la funesta enfermedad que atacó a la Emperatriz, y era que todos aquellos disgustos fueron a dar en un cerebro debilitado por los estudios, pues la Emperatriz Carlota era una muger sabia (Lombardo de Miramón, 1980: 511).

Según la viuda de Miramón, fue el orgullo y la ambición de Carlota los que fueron determinantes para la muerte del emperador: "Nada arredró a los jóvenes Príncipes para efectuar su marcha; la ambiciosa Carlota, arrastró a su infeliz esposo, para hacerlo subir las gradas de aquel maléfico trono, de los Aztecas y del mártir Iturbide. Así la funesta suerte de aquellos tres antecesores de Maximiliano lo hisieron partícipe de su desastroso fin" (Lombardo de Miramón, 1980: 645-646).

Al respecto es pertinente aclarar que pese a que Carlota alentó a su esposo para que éste aceptara la corona, el propio Maximiliano explicó en sus memorias los motivos que fueron decisivos para que hubiese aceptado el trono mexicano. Entre ellos figura el gusto por el exotismo, la búsqueda de lo primitivo y el deseo de llevar a los indígenas de su atraso económico y cultural a mejores condiciones de vida (De Habsburgo 1869: I, 121 y 141s.). Tanto esta visión romántica de su posible papel en México como su desconocimiento acerca de los intereses de los grupos políticos mexicanos, europeos y estadounidenses, y las resultantes decisiones equivocadas de Maximiliano que la propia Lombardo de Miramón señaló, contribuyeron al trágico desenlace del imperio y sus partidarios.

En lo que atañe a las evaluaciones que realizó la viuda en el párrafo antes citado, es pertinente subrayar que distorsionó también los hechos de la historia mexicana al establecer una línea de continuidad entre los emperadores aztecas que sucumbieron en la lucha contra los conquistadores, Iturbide, que no murió como mártir, sino porque no respetó las instituciones democráticas creadas tras la Independencia y porque con su suntuosa corte contribuyó al empobrecimiento del país, y, por fin, Maximiliano, que, aunque bien intencionado, violentó la soberanía de México.

Por todo lo anterior es evidente que Lombardo de Miramón no cumple con la pretendida objetividad y el propósito de proporcionar la verdad histórica. Al contrario, sus juicios parciales y la distorsión de algunos de los hechos se deben al odio que sintió contra los que fusilaron a su esposo y contra los que de algún modo fueron responsables en que éste regresara a México en defensa de Maximiliano, lo que hizo posible su captura 
y ejecución. Se deben también al dolor de haber perdido a su esposo a sólo ocho años de haber contraído matrimonio y a la consecuente pérdida de su posición social, así como al hecho de haber tenido que exiliarse y vivir lejos de México. Por otro lado, la viuda quiere crear una imagen positiva acerca de su esposo al que la historiografía de los vencedores presenta como antihéroe e incluso traidor. Con un tono intimista, emotivo, nostálgico y subjetivo describe un mundo pretérito no tal como fue, sino como ella lo anhela y lo imagina a partir de sus recuerdos. Además, en la manera en que comenta los sucesos de la historia nacional influye el hecho de que ella haga su evaluación e interpretación de los sucesos históricos desde la idiosincrasia de una mujer criolla proveniente de la clase alta mexicana, es decir, reconstruye el México de mediados del siglo XIX a partir de las convicciones y los valores basados en el catolicismo que comparte con los conservadores y no cuestiona en ningún momento.

\section{A modo de conclusión}

Lombardo de Miramón pertenece al pequeño grupo de mujeres que en la segunda mitad del siglo xx y el cambio de siglo construye su propio discurso con respecto a los acontecimientos históricos que convulsionaron al México independiente. Deja testimonio de cómo la vida de su esposo en tanto hombre público tuvo un fuerte impacto en la vida conyugal y familiar, pues ella tuvo que abandonar México al igual que muchos políticos conservadores y sus familiares. Así, el 13 de octubre de 1867 se embarcó con sus hijos en Veracruz rumbo a Europa donde recorrió varios países en calidad de exiliada: Alemania, Bélgica, Francia, Italia y España.

Pese a la falta de objetividad en sus opiniones políticas, las Memorias son valiosas en tanto documento en que se enuncia un contradiscurso al de la historia oficial y se comenta un proyecto político del partido conservador mexicano del siglo XIX: fundar un imperio mexicano con un soberano católico europeo para fortalecer la posición de México ante el imperialismo creciente de Estados Unidos, país predominantemente protestante. El texto pone además de relieve las contradicciones y la falta de acuerdo entre los que pertenecen al bando de los conservadores: Maximiliano fue imperialista al igual que los monarquistas dentro del grupo conservador, pero, a diferencia de este grupo político, fue enemigo del clero, lo que causó el distanciamiento entre él y los que lo habían apoyado inicialmente; a su vez, Miramón se opuso al sistema monárquico, más aún a una monarquía bajo el mando de un monarca extranjero, defendió la soberanía y el principio católico. El hecho de quedarse fiel a este principio, por su parte, impidió que llegara a un acuerdo con los liberales.

Aunque Concepción Lombardo de Miramón es el sujeto del discurso, pareciera que da voz a su marido y retoma sus puntos de vista. Del mismo modo, se ajusta a las expectativas de su tiempo acerca del comportamiento femenino; sólo cuando basado en su intuición temió seriamente por la vida de su cónyuge lo contradice y le suplica no adherirse en el último momento a la causa imperial si antes se había resistido a apoyar 


\section{$112 \square$ MEMORIAS DE CONCEPCIÓN LOMBARDO DE MIRAMÓN}

al Imperio. ${ }^{26}$ Pero acostumbrada a obedecer a su esposo, Lombardo de Miramón se resigna a no insistir más. Está tan acostumbrada a aceptar las opiniones y valores no sólo de su esposo, sino de los conservadores y la Iglesia, que ella defiende la forma de vida de las mujeres criollas de clase alta y la educación católica de las mismas pese a que por las educadoras de las Amigas, que carecían de formación pedagógica, fue sometida a severos castigos y sólo tuvo que memorizar el catecismo, los mandamientos, los rezos y la doctrina católica, pero no aprendió a escribir. Como muestran los párrafos arriba citados, una mujer como Carlota con amplios conocimientos, no obstante, para ella significó ser una amenaza en lugar de poder ser un modelo digno de imitación. La intolerancia que Concepción manifiesta con respecto a la forma de ser y actuar de Carlota asombra también porque realizó varios viajes a Europa antes de quedarse en calidad de exiliada en aquel continente y debió haberse percatado que en general las mujeres de la burguesía y aristocracia europeas tenían acceso a una amplia educación, dominaron frecuentemente diversos idiomas y tuvieron conocimientos acerca de las bellas artes, la literatura y la música.

A diferencia de Concepción que no vislumbra otro modo de ser para la mujer criolla, Dolores Bolio, inspirada en los modelos femeninos de Estados Unidos, propuso por medio de la configuración de doña Edelmira una imagen nueva para las mujeres de clase alta. A través del discurso de este personaje realizó una crítica en lo que atañe a la situación en la que se encontraban: "A las mujeres aristocráticas de mi tiempo no les era otorgado el don del pensamiento: nuestros saberes se reducían a idiomas y bordado, técnica musical, dibujo, recitación y baile" (Bolio, 1920: 40). Este personaje no sólo celebra el fin de una época y forma de vida, sino incluso la victoria del gobierno liberal y lo defiende delante de su confesor y los miembros de la aristocracia.

Para Concepción Lombardo de Miramón, sin embargo, es difícil resignarse al final de esta época marcada por el catolicismo y por costumbres heredadas de tiempos de la Colonia, porque los cambios sociales propuestos e impulsados por los liberales, la consecuente guerra civil y la guerra contra Francia provocaron que ella perdiera a su esposo y tuviera que abandonar a su país. Pese a la emotividad que por motivos obvios permea el texto de Lombardo de Miramón, su valor reside en el hecho de ser único en su calidad de testimonio sobre las prácticas culturales y costumbres de esta época, ${ }^{27}$ así como sobre la vida de una mujer cercana a los círculos del poder.

\footnotetext{
${ }^{26}$ Años antes, con motivo de la intercesión de Lombardo de Miramón por un militar que su esposo había condenado a muerte, éste la había reconvenido: "Señora, no me hable Usted de eso, mis Oficiales que se pasan con el enemigo, ya saben la suerte que les espera si caen pricioneros" (1980: 157). Desde entonces, ella no se había atrevido a expresar su opinión acerca de asuntos políticos y militares.

${ }^{27}$ Lombardo de Miramón alude, por ejemplo, a la práctica común desde tiempos de la Colonia que un confesor asumía el papel de tutor tras la muerte del padre de una joven. Aparte de quedar bajo la tutela de su confesor, en vista de ser pretendida por un joven protestante, ella solicitó ingresar a un convento, para que no hubiesen dudas acerca de su reputación y comportamiento virtuoso (cf. Lombardo de Miramón, 1980: 82).
} 
Obras citadas

Bolio, Dolores. 1920. Una hoja del pasado. México: Andrés Botas e Hijo.

CARBAllo, Emmanuel. 1992. "Prólogo. Concha Lombardo, heroína del romanticismo mexicano". Concepción LOMBARDO DE MIRAMÓN. Memorias de una primera dama. México: Grijalbo. Pp. 9-14.

DíAZ, Lilia. 1981 [1976]. "El liberalismo militante". Historia general de México. 3a. ed. Tomo 2, coordinado por Daniel Cosío Villegas. México: El Colegio de México. Pp. 819-896.

DOMENELlA, Ana Rosa y Nora PASTERNAC, eds. 1991. Las voces olvidadas. Antología crítica de narradoras mexicanas nacidas en el siglo XIX. México: El Colegio de México.

EJÉRCITO DE OpERACIONES. 1980 [1968]. “Causa de Fernando Maximiliano de Hapsburgo que se ha titulado Emperador de México y sus llamados Generales Miguel Miramón y Tomás Mejía, sus cómplices". Concepción LOMBARDO DE MiRAMÓN. Memorias. México: Porrúa. Pp. 891-944.

FoussemaGne, Reinach. 1925. Charlotte de Belgique. Impératrice du Mexique. París: Plon.

HabsbuRgo, Maximiliano de. 1869. Recuerdos de mi vida. Memorias de Maximiliano. Trad. José LinARES y Luis MÉnDEZ. México: F. Escalante.

Hidalgo y Esnaurrízar, José Manuel. 1978. Cartas. 2a. ed. Recop., pról. y notas de Sofía Verea de Bernal. México: Porrúa.

IBARRA, Domingo. 1980. "Extractos de la vida militar del Gral. Miguel Miramón”. Concepción Lombardo de Miramón. Memorias. México: Porrúa. Pp. 883-885.

1890. Episodios históricos militares que ocurrieron en la República Mexicana desde fines del año 1838 hasta el de 1860: con excepción de los hechos de armas que hubo en tiempos de la invasión norteamericana. México: Reyes Velasco.

LOMBARDO DE MiRAmón, Concepción. 1992. Memorias de una primera dama. México: Grijalbo. 1980. Memorias. México: Porrúa.

MÉndeZ DE CuenCA, Laura. 1983 [1910]. Simplezas. México: INBA / Premiá.

Miramón, Miguel. 1980. Cartas, en Concepción LOMBARdo DE MirAMÓn. Memorias. México: Porrúa. Pp. 680-874.

RAMOS EsCANDÓn, Carmen. 1991. "Memoria de mujer. Concepción Lombardo de Miramón, testiga de sí misma". Ana Rosa Domenella y Nora PASTERnAC, eds. Las voces olvidadas. Antología crítica de narradoras mexicanas nacidas en el siglo XIX. México: El Colegio de México. Pp. 265-280.

Salm Salm, Agnés de. 1869. Querétaro: apuntes del diario de la princesa Inés de Salm Salm. México: Tomás F. Neve. 